\title{
UM ESTUDO SOBRE OS CONCURSOS PÚBLICOS PARA ARQUIVISTA NO BRASIL
}

\author{
Karina Xavier Holstein \\ Bacharel em Arquivologia \\ kaka.holstein@hotmail.com \\ Moisés Rockembach \\ Doutor em Informação e Comunicação em Plataformas Digitais \\ Professor do Curso de Arquivologia e do PPGCOM-UFRGS \\ moises.rockembach@ufrgs.br
}

\section{Resumo}

\begin{abstract}
O estudo teve como objetivo uma análise dos diferentes aspectos relacionados às provas de concurso público para Arquivista no Brasil, buscando reconhecer as relações entre os principais assuntos exigidos nas questões e o referencial teórico arquivístico. Como procedimentos metodológicos, identificou as áreas de maior destaque da Arquivologia no âmbito das questões e desenvolveu levantamentos qualitativo e quantitativo dos resultados, bem como análise da distribuição geográfica das provas. Os dados demonstraram que os tópicos não são cobrados com a mesma proporção e que certos assuntos importantes são negligenciados, ao mesmo tempo em que a citação de bibliografia é escassa. Os resultados indicaram que há concentração maior de concursos para Arquivista em regiões onde há curso de graduação na área.
\end{abstract}

Palavras-chave: Arquivologia. Concurso Público. Mapeamento Geográfico. Referencial Teórico.

\section{INTRODUÇÃO}

Os concursos públicos são, para muitos, um objetivo na vida profissional devido aos diversos atrativos que apresentam. A estabilidade, os planos de carreira e a possibilidade de receber uma remuneração superior à média, logo após a graduação, são apenas alguns dos benefícios para que um número significativo de pessoas invista tempo e dinheiro na preparação para concorrer ao almejado cargo público e essa realidade se repete para boa parte dos profissionais formados em Arquivologia.

Devido à relevância do serviço público no planejamento de carreira de muitos profissionais da área, foi verificada a necessidade de estudos que relacionassem a Arquivologia e os concursos públicos, visto que há escassez na produção de trabalhos acadêmicos e artigos científicos sobre o tema. Por este motivo, essa pesquisa visou apresentar análises de pontos considerados relevantes para o conhecimento daqueles que pretendem participar desses processos seletivos, mas sobretudo para uma melhor compreensão da própria área de estudo, em entender como estas seleções têm sido produzidas.

Foi estabelecida a análise e definição do tema principal de cada uma das questões de conhecimentos específicos cobradas nas provas de concursos públicos para o cargo de Arquivista no Brasil, com realização entre janeiro de 2014 e junho de 2016. Para tanto, definimos como problema de pesquisa a pergunta: "qual a relação entre os principais assuntos de conhecimentos específicos exigidos pelos concursos para Arquivista e o referencial teórico arquivístico?". Também foi elaborada crítica referente aos tópicos mais recorrentes e às razões pelas quais alguns outros são negligenciados, bem como mapeamento das provas de acordo com as regiões do país.

Espera-se que o conteúdo aqui apresentado tenha demonstrado certos padrões nas questões e auxilie na elaboração de provas de seleção. Também foram propostos outros temas de pesquisa que podem ser decorrentes dos resultados aqui obtidos e cujo aprofundamento teórico poderá contribuir para o 
desenvolvimento como área de conhecimento e como profissão.

\section{A ARQUIVOLOGIA E SEUS EIXOS TEMÁTICOS}

Responsável pela formação de profissionais cuja principal atividade é garantir o acesso à informação àqueles que dela necessitam, a Arquivologia é composta por diferentes ramos do saber que, juntos, proporcionam um aprendizado interdisciplinar e a capacidade de compreensão da estrutura, evolução, funções e atividades institucionais para transformar os dados dos documentos em informação para o usuário; capacidades, estas, que necessitam do auxílio de bases, princípios e técnicas para serem desenvolvidas (BELLOTTO, 2014). Nesse sentido, é fundamental que o currículo do Arquivista englobe disciplinas que estimulem as habilidades críticas e, ao mesmo tempo, forneçam conhecimento prático para lidar com a informação em seus mais variados suportes.

Uma das importantes mudanças históricas de direcionamento na formação profissional e estudo da disciplina arquivística no século passado surge com o conceito de records management, que passa a envolver não só os arquivos históricos, mas a possibilidade do profissional em atuar nas fases de produção e tramitação de documentos (SILVA et al., 1998). A arquivística integrada (ROUSSEAU, COUTURE, 1998) e a emergência do paradigma póscustodial e da informação como objeto de estudo (SILVA, 2006) vem a complementar estas mudanças sentidas no âmbito profissional.

$\mathrm{O}$ século XX e início de século XXI trouxeram novidades e anseios para a área da documentação, pois com o surgimento da Internet e o crescimento exponencial dos documentos digitais houve a impressão de que, em breve, o trabalho do arquivista seria dispensável. No entanto, ocorreu justamente o contrário e, atualmente, a batalha pela transparência no setor público vem criando grande pressão perante os órgãos e instituições, cenário que ampliou a demanda por bacharéis em Arquivologia. Conforme expresso na Constituição de 1988 "compete à administração pública, na forma da lei, a gestão de sua documentação governamental e as providências para franquear sua consulta a quantos dela necessitem" (BRASIL, 1988), e o arquivista desempenha papel fundamental nesse processo. Ademais, em 2011, a Lei de Acesso à Informação (Lei $\left.n^{\circ} 12.527\right)$ passou a regular os procedimentos que visam a assegurar o direito fundamental de acesso à informação, exigindo sua execução em conformidade com os princípios básicos da Administração Pública e evidenciando ainda mais a importância do profissional responsável pelos arquivos. A crescente necessidade desses profissionais, por sua vez, fez aumentar o número de processos seletivos públicos.

No âmbito desses concursos, é importante esclarecer que as provas para seleção de candidatos com nível superior geralmente contemplam outras matérias além dos conhecimentos específicos exigidos para o cargo. Conforme apontado por Cavallini (2008) "as disciplinas que fazem parte das provas específicas são diretamente ligadas à área de formação do candidato (no caso de nível superior de escolaridade) e ao cargo concorrido". Além disso, o peso atribuído a essas questões é frequentemente maior, visto que são consideradas fundamentais para que o candidato venha a ter um bom desempenho no cargo. Já os conhecimentos básicos costumam ser comuns a diferentes cargos e exigem, principalmente, disciplinas como Português, Matemática, Raciocínio Lógico, Informática e Inglês. Por esse motivo o estudo dos temas específicos é tão importante para aqueles que pretendem conquistar uma vaga no setor público.

$\mathrm{Na}$ Arquivologia as opções de temas principais defendidas pelos autores são variadas e, por isso, foi necessária análise que tornasse possível a elaboração de uma única proposta de tópicos arquivísticos, capaz de englobar todos os assuntos abordados nas provas. Nessa pesquisa se optou por utilizar três obras de referência para compor o quadro de análise. A primeira é a seleção de temas de destaque apresentada por Couture, Martineau e Ducharme (1999), a qual foi baseada em levantamentos bibliográficos. De acordo com os autores "o estudo das estruturas dos cursos sugere a existência de uma preponderância cada vez maior da parte arquivística" sendo suficiente que os ensinamentos dos outros saberes que contribuem para a formação do arquivista sejam orientados "em função das necessidades específicas da arquivística" (COUTURE; MARTINEAU; DUCHARME, 1999, p.42).

A constatação de Couture, Martineau e Ducharme, que indica o crescimento da importância de disciplinas específicas no currículo da Arquivologia, foi observada também por outro modelo selecionado para análise, cuja publicação ocorreu quinze anos depois, em 2014. Nessa segunda proposta, Bellotto confere destaque às três idades do ciclo de vida documental, primando pelo ensino da 
arquivística fundamental enquanto as chamadas 'disciplinas auxiliares' servem como complemento ao plano de ensino. Embora a autora faça referência à alta complexidade e dificuldade da prática de conciliar o ensino de arquivos correntes e históricos em uma mesma formação, também esclarece que tal procedimento é fundamental para que haja "unicidade da função arquivística" (BELLOTTO, 2014, p.207).

A terceira referência utilizada como base para esta pesquisa foram os temas elencados por Jardim (2012) como áreas que merecem destaque e que são tendências na pesquisa em Arquivologia. A proposta curricular e as investigações na área são indissociáveis, uma vez que tais estudos refletem o futuro da disciplina e é fundamental que estejam contemplados nos planos de ensino. Nesse sentido, o autor afirma que alguns tópicos "merecem reflexão com vistas à definição de programas de pesquisa" (JARDIM, 2012, p.147), visto que ela "tem implicação direta nos modelos e práticas de formação do arquivista na graduação e na pós-graduação" (JARDIM, 2012, p.152).

A partir da análise dos temas elencados nas três obras citadas foi possível elaborar uma proposta de currículo que englobou todos os tópicos cobrados nas questões das provas estudadas. Tal proposta foi dividida em dois grupos: "Arquivística pura" e "Disciplinas conexas", e essa classificação obedeceu a critérios que consideraram tanto a importância quanto a origem de tais atividades no contexto arquivístico. Por exemplo, temas como "Preservação, conservação e restauração", "Documentos digitais" e "Digitalização", ainda que possuam forte relação com as atividades do Arquivista, foram aqui definidos como "Disciplinas conexas" porque não possuem sua origem na Arquivologia e seus conceitos na conjuntura dessa pesquisa estavam relacionados aos seus conteúdos fundamentais e não às suas intersecções com a área.

Nos quadros a seguir poderão ser observados os resultados desse levantamento bibliográfico, cujos tópicos foram posteriormente utilizados para classificar as questões. Nas colunas da esquerda de cada quadro (Arquivística pura e Disciplinas conexas) estão identificados os temas definidos nesta pesquisa, e à direita estão detalhadas as referências em que cada um dos assuntos teve origem. Nas obras de Bellotto (2014) e Couture, Martineau e Ducharme (1999) a disciplina foi dividida em tópicos e subtópicos, característica que se optou por manter na citação. Para tanto, foi mencionado o tema geral e após, entre parênteses, a terminologia exata utilizada pelos autores.

Quadro 1-Categorias temáticas para análise: arquivística pura

\begin{tabular}{|c|c|}
\hline Arquivística pura & Referências \\
\hline Fundamentos de Arquivologia & $\begin{array}{l}\text { - Bellotto, 2014: Introdução à Arquivologia (conceitos gerais); } \\
\text { - Couture, Martineau e Ducharme, 1999: Arquivística pura (arquivística } \\
\text { fundamental). }\end{array}$ \\
\hline História arquivística & $\begin{array}{l}\text { - Bellotto, 2014: Introdução à Arquivologia (histórico); } \\
\text { - Couture, Martineau e Ducharme, 1999: História sob medida (história dos } \\
\text { arquivos). }\end{array}$ \\
\hline Terminologia & - Bellotto, 2014: Introdução à Arquivologia (terminologia). \\
\hline Gestão documental & $\begin{array}{l}\text { - Bellotto, 2014: Arquivo corrente (gestão de documentos); } \\
\text { - Couture, Martineau e Ducharme, 1999: Arquivística pura (gestão de } \\
\text { documentos). }\end{array}$ \\
\hline Classificação e avaliação & $\begin{array}{l}\text { - Bellotto, 2014: Arquivo corrente (classificação, avaliação); } \\
\text { - Couture, Martineau e Ducharme, 1999: Arquivística pura (funções } \\
\text { arquivísticas). }\end{array}$ \\
\hline Arranjo e descrição & $\begin{array}{l}\text { - Bellotto, 2014: Arquivo permanente (arranjo, descrição); } \\
\text { - Couture, Martineau e Ducharme, 1999: Arquivística pura (funções } \\
\text { arquivísticas). }\end{array}$ \\
\hline Políticas arquivísticas & $\begin{array}{l}\text { - Bellotto, 2014: Introdução à Arquivologia (políticas); } \\
\text { - Couture, Martineau e Ducharme, 1999: Arquivística pura (políticas e } \\
\text { gestão de programas arquivísticos); } \\
\text { - Jardim, 2012: Políticas arquivísticas. }\end{array}$ \\
\hline Legislação arquivística & $\begin{array}{l}\text { - Bellotto, 2014: Introdução à Arquivologia (legislação); } \\
\text { - Couture, Martineau e Ducharme, 1999: Arquivística pura (legislação e } \\
\text { questões jurídicas). }\end{array}$ \\
\hline
\end{tabular}




\begin{tabular}{|c|c|}
\hline Gestão Institucional & $\begin{array}{l}\text { - Couture, Martineau e Ducharme, 1999: Arquivística pura (gestão dos } \\
\text { arquivos); } \\
\text { - Jardim, 2012: gestão de serviços e instituições arquivísticas. }\end{array}$ \\
\hline Normatização & - Jardim, 2012: Normalização. \\
\hline Difusão & $\begin{array}{l}\text { - Bellotto, 2014: Arquivo permanente (ação cultural e educativa dos } \\
\text { arquivos); } \\
\text { - Couture, Martineau e Ducharme, 1999: Arquivística pura (funções } \\
\text { arquivísticas); } \\
\text { - Jardim, 2012: usos e usuários da informação arquivística. }\end{array}$ \\
\hline Perfil profissional & $\begin{array}{l}\text { - Bellotto, 2014: Introdução à Arquivologia (campus de atuação); } \\
\text { - Couture, Martineau e Ducharme, 1999: História sob medida (história da } \\
\text { profissão de arquivista); } \\
\text { - Jardim, 2012: o perfil da atividade arquivística. }\end{array}$ \\
\hline Aquisição & $\begin{array}{l}\text { - Couture, Martineau e Ducharme, 1999: Arquivística pura (funções } \\
\text { arquivísticas). }\end{array}$ \\
\hline Arquivos específicos & $\begin{array}{l}\text { Este tópico foi criado devido à necessidade de classificar questões que } \\
\text { versavam especificamente sobre o arquivo da instituição contratante, não } \\
\text { podendo ser classificadas em outro tópico. }\end{array}$ \\
\hline
\end{tabular}

Fonte: elaborado pelos autores.

Quadro 2-Categorias temáticas para análise: disciplinas conexas

\begin{tabular}{|c|c|}
\hline Disciplinas conexas & Referências \\
\hline $\begin{array}{l}\text { Preservação, conservação e } \\
\text { restauração }\end{array}$ & $\begin{array}{l}\text { - Bellotto, 2014: Disciplinas instrumentais (preservação e restauração); } \\
\text { - Couture, Martineau e Ducharme, 1999: Ciências da informação (preservação } \\
\text { e conservação); } \\
\text { - Jardim, 2012: Preservação. }\end{array}$ \\
\hline Documentos digitais & $\begin{array}{l}\text { - Bellotto, 2014: Disciplinas instrumentais (informática); } \\
\text { - Couture, Martineau e Ducharme, 1999: Ciências da Informação (utilização } \\
\text { de novas tecnologias); } \\
\text { - Jardim, 2012: Documentos digitais. }\end{array}$ \\
\hline Digitalização & $\begin{array}{l}\text { - Bellotto, 2014: Disciplinas instrumentais (informática); } \\
\text { - Couture, Martineau e Ducharme, 1999: Ciências da Informação (utilização } \\
\text { de novas tecnologias). }\end{array}$ \\
\hline Ciência da Informação & $\begin{array}{l}\text { - Couture, Martineau e Ducharme, 1999: Ciência da Informação (fundamentos } \\
\text { da Ciência da Informação). }\end{array}$ \\
\hline Estatística & - Bellotto, 2014: Disciplinas instrumentais (estatística). \\
\hline Paleografia & - Bellotto, 2014: Disciplinas instrumentais (paleografia). \\
\hline Diplomática & $\begin{array}{l}\text { - Bellotto, 2014: Disciplinas instrumentais (diplomacia); } \\
\text { - Couture, Martineau e Ducharme, 1999: Arquivística pura (diplomática e } \\
\text { arquivística descritiva). }\end{array}$ \\
\hline Microfilmagem & $\begin{array}{l}\text { - Bellotto, 2014: Disciplinas instrumentais (microfilmagem); } \\
\text { - Couture, Martineau e Ducharme, 1999: Arquivística pura (suportes } \\
\text { especiais). }\end{array}$ \\
\hline
\end{tabular}

Fonte: elaborado pelos autores.

Cada um dos temas indicados acima possui subdivisões que orientam o estudo acadêmico, e cada subdivisão pode ser interpretada a partir de conceitos distintos de acordo com o autor escolhido. No entanto, é importante destacar que o objetivo desta pesquisa não foi identificar divergências entre as propostas, e sim compilar os tópicos mais importantes para possibilitar que a análise do objeto de estudo dessa pesquisa fosse realizada da maneira mais completa possível.

\section{PROCEDIMENTOS METODOLÓGICOS}


$\mathrm{O}$ tipo de pesquisa que se mostrou mais adequado para responder às questões propostas foi a abordagem quanti-qualitativa. A abordagem qualitativa foi relevante, pois não se buscavam somente resultados exatos e mensuráveis, mas também a interpretação dos dados coletados e a atribuição de significados, utilizando o ambiente natural como principal fonte de informações. No entanto, a definição da abordagem qualitativa como forma de encontrar respostas ao problema de pesquisa não excluiu a utilização de dados numéricos e abordagem quantitativa, com levantamento estatístico dos assuntos das questões, pois eles foram indispensáveis para este trabalho no momento de realizar o mapeamento da frequência com que os temas foram abordados nas provas.

Considerando que a definição do problema de pesquisa é vital para auxiliar no direcionamento do estudo, propôs-se a seguinte pergunta: quais os principais conhecimentos específicos exigidos pelos atuais concursos públicos para o cargo de Arquivista no Brasil e como se dá sua relação com o referencial teórico arquivístico? A partir desse questionamento foram descritas as características dos dados encontrados - identificando, registrando e analisando as relações entre as variáveis. Para tanto, foi definido como objetivo geral a análise dos tópicos cobrados nas provas de concursos públicos para o cargo de Arquivista no Brasil, com realização entre janeiro de 2014 e junho de 2016, estabelecendo relações com as referências bibliográficas utilizadas e realizando um mapeamento das provas no contexto nacional.

Os objetivos específicos, por sua vez, foram relacionar os concursos públicos para Arquivista cujas provas foram realizadas no período delimitado no objetivo geral e que integram a base de dados do website PCI Concursos; estabelecer o assunto de cada uma das questões das provas selecionadas de acordo com as categorias de análise; elaborar levantamento estatístico dos assuntos cobrados nas questões; identificar as principais referências bibliográficas utilizadas para a elaboração das questões e; comparar os conhecimentos exigidos nas provas com o referencial teórico arquivístico.

Os procedimentos técnicos empregados na investigação envolveram a pesquisa bibliográfica e documental, visto que foram utilizados tanto materiais já publicados por outros autores, quanto documentos que ainda não tinham recebido qualquer tratamento analítico.

Portanto, foi a partir do estudo das provas que as informações dispersas puderam ser reunidas de maneira lógica e com o estabelecimento de relações entre si que resultaram na análise e conclusão deste trabalho. $\mathrm{O}$ procedimento bibliográfico foi indispensável nesse processo, sendo a escolha da bibliografia feita considerando as principais referências na área da Arquivologia e exercendo papel fundamental na delimitação dos tópicos selecionados para a classificação

Todas as questões analisadas no trabalho foram retiradas da matéria de conhecimentos específicos de provas para o provimento de cargos de Arquivista aplicadas no Brasil. O critério utilizado na escolha das provas foi temporal, para evitar a inclusão de provas muito antigas, e englobou todos os arquivos constantes na base de dados do website PCI Concursos datadas de janeiro de 2014 a junho de 2016 sendo, ao todo, selecionadas 68 provas. O website escolhido consiste em uma das mais completas bases de dados de provas de concurso existentes no país.

Inicialmente, o material foi organizado em uma planilha do aplicativo Excel na qual foram registradas as informações consideradas mais relevantes para a correta identificação e recuperação de cada documento: nome do cargo, banca organizadora, órgão/instituição para qual o concurso será prestado, mês e ano de aplicação da prova e quantidade de questões de conhecimentos específicos; cada prova também recebeu uma numeração única entre 1 e 68.

$\mathrm{Na}$ etapa seguinte, cada um dos itens listados na primeira planilha foi detalhado em uma segunda planilha. Esse instrumento serviu para analisar as questões uma a uma e verificar qual tópico dentre aqueles pré-definidos se mostrava mais compatível com o conhecimento exigido. Foram identificados também os subtópicos de cada questão, bem como as referências bibliográficas e o seu respectivo ano, quando especificados na questão.

Ao final foram contabilizadas 1847 questões, das quais 39 tratavam de assuntos não relacionados à Arquivologia e 16 foram anuladas pela banca organizadora, resultando em um total de 1792 questões e 2214 tópicos principais. O número de assuntos foi superior devido ao fato da possibilidade em haver mais de um tema em uma única questão. Os resultados obtidos com a classificação tornaram possível identificar a frequência com que cada tópico foi cobrado no conjunto de provas selecionadas, bem como forneceram subsídios para responder ao problema de pesquisa proposto por este trabalho.

É fundamental destacar que, embora essa pesquisa tenha utilizado como meio para coleta dos materiais um dos websites mais completos e atualizados na área de concursos públicos no Brasil, não há como 
assegurar que tal base de dados contempla na totalidade os concursos promovidos no recorte temporal aqui definido. No entanto, dada a quantidade de provas coletadas e questões analisadas,

estões, ainda que dos 2214 tópicos encontrados apenas 642 tenham apresentado citação das referências. Tal realidade, apesar de limitar o estudo da bibliografia pelo fato de não apresentar referências

\section{PANORAMA BRASILEIRO DOS CONCURSOS PÚBLICOS PARA ARQUIVISTA}

Após o levantamento quantitativo de cada um dos temas das questões, foram identificados sete assuntos acredita-se que os resultados obtidos são fiéis representantes da realidade.

A relação entre as questões estudadas e o referencial teórico arquivístico foi feita através das referências bibliográficas mencionadas nas qu

com frequência, demonstrou importantes características das provas de concursos públicos para Arquivista e gerou aspectos interessantes para análise.

principais, os quais registraram mais de 150 ocorrências cada, e outros 15 assuntos com menos de 150 ocorrências cada. Os resultados obtidos podem ser observados detalhadamente no gráfico abaixo, que engloba todos os eixos temáticos encontrados:

Gráfico 1- Distribuição dos tópicos nas provas analisadas

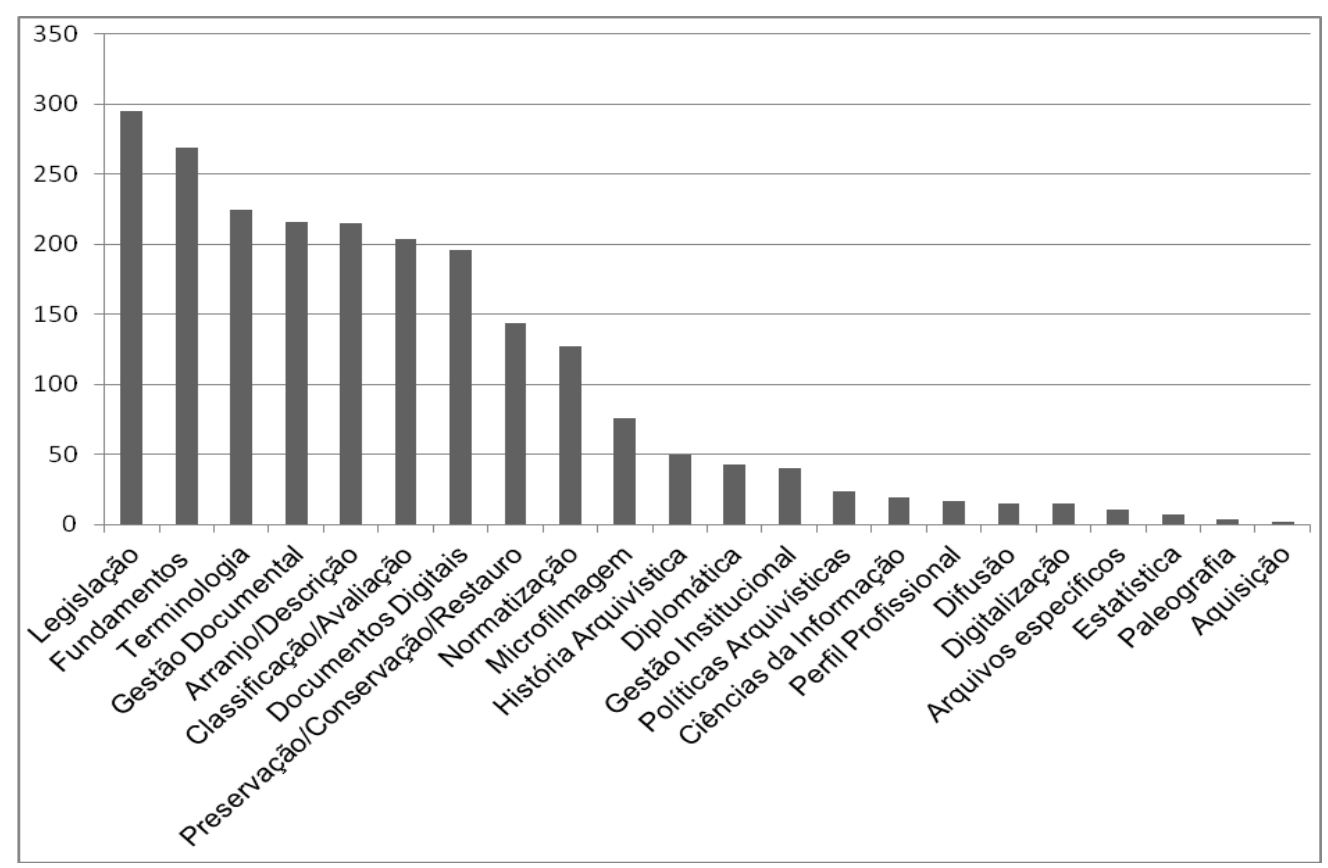

Fonte: elaborado pelos autores.

As questões referentes a Fundamentos de Arquivologia, Legislação, Terminologia, Gestão Documental, Arranjo/Descrição, Classificação/Avaliação e Documentos Digitais foram identificadas como sendo as mais recorrentes no conjunto de provas analisadas. Acredita-se que esse resultado se deu devido à substancialidade das referidas temáticas para a adequada execução do trabalho do Arquivista. No total, os sete destaques especificados acima foram identificados em $73,17 \%$ dos tópicos encontrados, enquanto os outros 15 assuntos juntos correspondem a somente $26,83 \%$ dos resultados.

E possível observar que os números estão muito distantes de serem homogêneos - situação que também não representaria o cenário ideal, mas, ao menos, proporcionaria maior visibilidade a algumas áreas importantes que são negligenciadas. Considerando que as 68 provas selecionadas continham um total de 1847 questões, a quantidade média de questões por prova é de 27,16. Multiplicando-se esse valor médio pela porcentagem 
referente aos 7 tópicos principais $(73,17 \%)$ encontrase o valor 19,87 . Isso significa que uma prova com 27,16 questões teria um total de 19,87 destas versando apenas sobre os 7 assuntos - o que resultaria em quase 3 questões para cada - enquanto as 7,29 questões restantes teriam que ser divididas para contemplar o máximo possível dos 15 tópicos remanescentes.

É normal que alguns tópicos possuam maior utilidade no dia a dia do Arquivista quando comparados a outros, no entanto, as ações de Difusão têm se mostrado de grande relevância nas instituições arquivísticas como forma de promoção do acervo e, ainda assim, encontram espaço em menos de $1 / 4$ das provas analisadas. $\mathrm{O}$ cenário identificado nesta pesquisa demonstra que não há preocupação por parte das bancas organizadoras e, principalmente, das instituições contratantes, visto que geralmente são elas que determinam os assuntos a serem tratados nas questões, em abordar a Arquivologia de uma maneira completa, considerando suas diversas ramificações. As provas estão focadas em alguns poucos tópicos e isso acaba influenciando na maneira como os profissionais da área se preparam para as seleções pois, considerando que não é comum a cobrança de determinados temas, os candidatos acabam focando seus estudos em apenas alguns pontos e as matérias já negligenciadas acabam sendo esquecidas ainda mais, prejudicando o desenvolvimento da disciplina.

A análise de citação de referências bibliográficas, por sua vez, permitiu concluir que a inclusão da fonte pode não ser considerada uma prática frequente. Dos 2214 tópicos listados durante a classificação das questões apenas 642 continham menção às obras consultadas, o que representa um total de $28,99 \%$. A fim de analisar as bibliografias citadas foi elaborada uma divisão inicial em quatro grupos, sendo estes: obras de referência da disciplina, normas, legislação e Dicionário Brasileiro de Terminologia Arquivística (DBTA). Tais classes foram definidas por terem apresentado destaque durante a análise e representarem $85 \%$ do total de 642 referências encontradas. Os $15 \%$ restantes são referentes a publicações mais específicas no âmbito da instituição contratante ou de autores pouco recorrentes. No gráfico abaixo é possível observar os resultados:

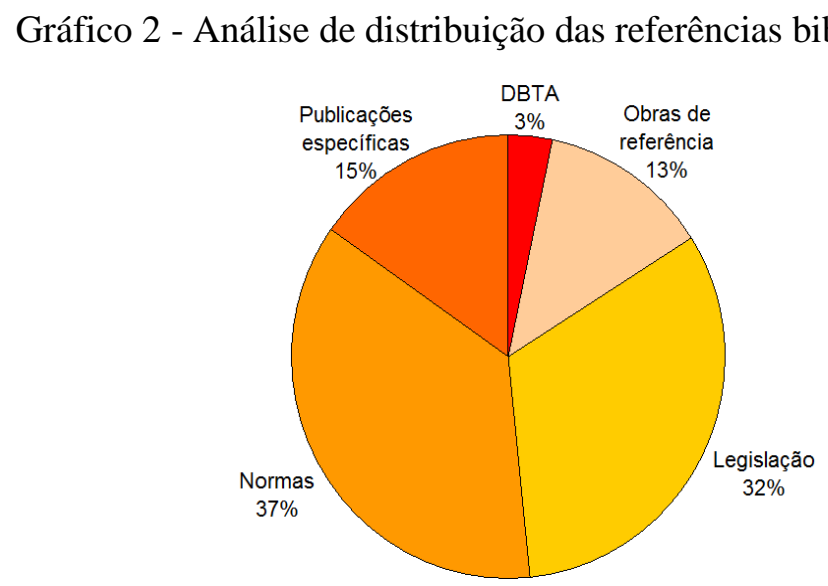

Fonte: elaborado pelos autores.

É possível observar que "Legislação" e "Normas arquivísticas" apresentam destaque, contando com um total de citações maior quando comparadas às obras de referência da disciplina. Tal realidade é preocupante, visto que as obras de referência são as bases do conhecimento arquivístico e a origem de todos os princípios, teorias e conceitos sob os quais a disciplina é construída. No entanto, é compreensível tal resultado se o analisarmos pelo ponto de vista da banca organizadora do concurso, a qual busca se proteger e evitar possíveis recursos contra questões mal formuladas. Nesse caso a utilização de leis e normas é benéfica, pois há facilidade para pontuar tópicos que poderão ser cobrados e as chances de evitar a subjetividade - e com isso a dupla interpretação - são maiores.

As referências de legislação incluem decretos, leis, medidas provisórias e resoluções, além da Constituição Federal. Já as citações a partir das normas focaram em cinco publicações da Arquivologia, com destaque para duas: e-ARQ Brasil (Modelo de Requisitos para Sistemas Informatizados de Gestão Arquivística de Documentos) e NOBRADE (Norma Brasileira de Descrição 
Arquivística). Considerando a mais frequente e atual aplicação prática das duas normas (e-ARQ Brasil para arquivos ativos e NOBRADE para arquivos inativos), pode-se dizer que há boa divisão de proporção entre elas, que, por coincidência, registraram igual quantidade de ocorrências nesta pesquisa. As outras três normas - ISAD $(G)$ (Norma Geral Internacional de Descrição Arquivística), ISAAR(CPF) (Norma Internacional de Registro de Autoridade Arquivística para Entidades Coletivas, Pessoas e Famílias) e ISDF (Norma Internacional para Descrição de Funções) - são utilizadas majoritariamente no âmbito dos arquivos permanentes, resultado compreensível considerando a pouca existência de normas referentes à gestão documental e a divulgação, ainda menor, das que já existem.

É fundamental destacar também a importância da maior referência à NOBRADE quando comparada à
$\operatorname{ISAD}(\mathrm{G})$, visto que a primeira é uma adaptação da segunda à realidade brasileira. Os números mostram que há preferência pela utilização da norma adaptada, o que reflete certa preocupação em fortalecer a utilização da bibliografia nacional e priorizar a aplicação de padrões brasileiros nos arquivos do país. Tal resultado é bastante relevante no campo da Arquivologia, em razão de grande parte das referências da área ser estrangeira e servir como base para o ensino da disciplina nas universidades brasileiras.

Assim como a análise das normas, o resultado da avaliação das obras mais referenciadas pelas bancas também indica a priorização de referências brasileiras em detrimento de grandes nomes da Arquivologia internacional. Os autores que se destacam por aparecerem com maior frequência estão representados a seguir:

Gráfico 3: Frequência de citação de autores da área

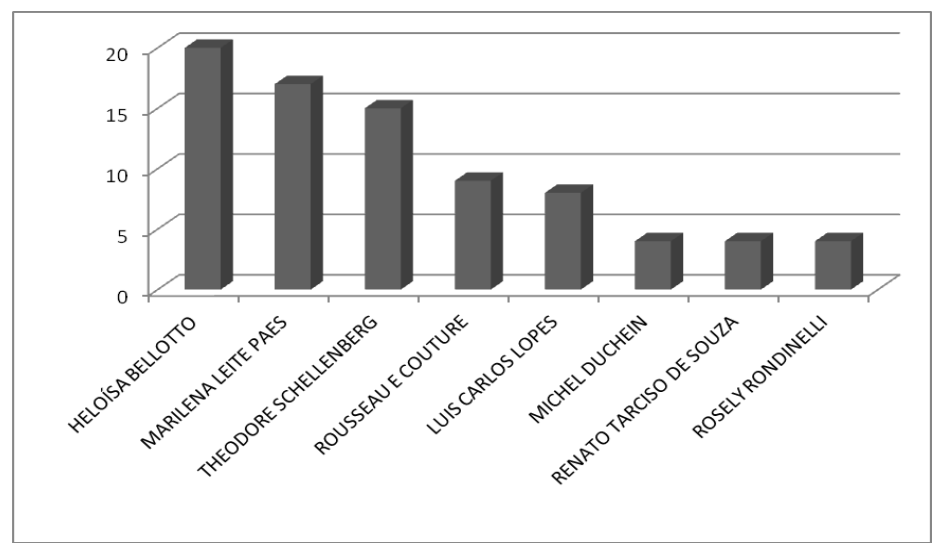

Fonte: elaborado pelos autores.

Conforme pode ser observado no gráfico, há predominância de títulos brasileiros nas obras de referência da Arquivologia, sendo estes os responsáveis por mais de $65 \%$ das bibliografias de autores mencionadas nas questões. Tal resultado reforça a ideia de que há uma priorização nas escolhas feitas pelas bancas organizadoras que contribui para a solidificação do conhecimento da arquivística brasileira. Assim como qualquer outra, a produção de conteúdo no país seria muito menos relevante se os principais processos seletivos abordassem prioritariamente definições internacionais ao invés de incentivar a leitura de autores locais.

$\mathrm{Na}$ maioria das vezes as questões não fazem menção direta ao título da obra de cada autor, no entanto, a partir da data de publicação das referências citadas foi possível identificar que pouco mais da metade teve sua primeira publicação no fim dos anos 1990, enquanto o restante data dos anos 2000. Observa-se, portanto, que embora haja a utilização de obras relativamente recentes, cujo conteúdo teórico é extremamente relevante para o desenvolvimento da disciplina, não há detrimento daquelas considerados como clássicos da Arquivologia. O fato das bancas organizadoras reconhecerem a relevância das origens da área, sem abandonar a utilização de referências atuais, propicia a consolidação do conhecimento já difundido e, ao mesmo tempo, estimula a produção de novos materiais.

O levantamento feito na primeira etapa de análise permitiu a exploração de mais um aspecto referente 
aos certames. Após identificar a localidade oficial da entidade contratante foi possível mapear os resultados e concluir que, a nível nacional, existe a tendência maior de concentração de provas próximas aos grandes centros urbanos, podendo ser percebidas apenas algumas exceções de concursos realizados fora dessas zonas. A figura a seguir representa a localização de cada órgão/instituição contratante do conjunto de provas analisadas:

Figura 1 - Localização geográfica das provas analisadas

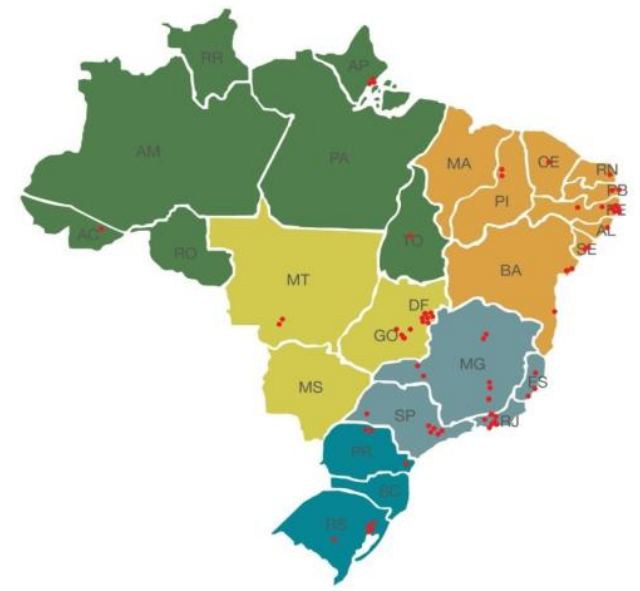

Fonte: elaborado pelos autores.

Com a identificação do endereço das instituições que oferecem curso de Arquivologia na modalidade presencial foi possível concluir também que as provas aplicadas seguem uma tendência de localização similar à dos cursos, indicando que a existência da graduação em determinada localidade próxima pode ser um fator que influencia a criação de vagas e a consequente seleção pública por meio de concurso. A imagem abaixo ilustra os resultados:

Figura 2: Localização geográfica dos cursos de Arquivologia

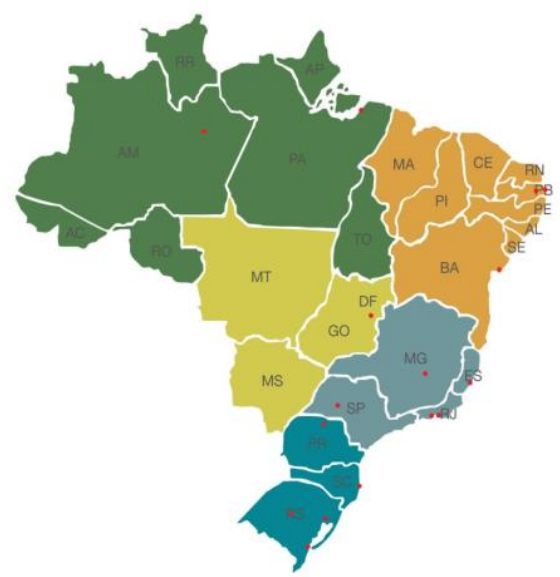

Fonte: elaborado pelos autores.

No entanto, também é possível constatar que tal tendência não é proporcional em cada região, ou seja, a presença de um maior número de cursos não indica, necessariamente, que aquela zona apresentará o maior número de concursos. Pode-se observar justamente o oposto ao tratarmos da região Sul, por exemplo. De acordo com os dados compilados a região Sul apresenta, juntamente com a região Sudeste, o maior número de cursos de Arquivologia do país, com cinco ocorrências cada. $\mathrm{O}$ número de provas aplicadas nessas duas regiões, por sua vez, foi bastante divergente. Enquanto a região Sul contabilizou oito provas aplicadas, a região Sudeste apresentou 23, ou seja, quase três vezes mais. Pode- 
se concluir, portanto, que não há relação direta aparente entre a quantidade de cursos e a de provas aplicadas em determinada região, mas que, conforme demonstrado anteriormente, os concursos parecem apresentar uma tendência de localização similar à de áreas que possuem a referida graduação.

Também foi possível identificar que a estimativa populacional de cada Unidade da Federação também não aparenta ter qualquer relação com a quantidade de concursos aplicados nesta, ou seja, não se pode concluir que quanto mais pessoas residirem em um estado maior será a quantidade de provas para o cargo de Arquivista lá registradas. A fim de corroborar tal afirmação foi elaborado levantamento da estimativa populacional de cada estado no ano 2016. Os dados indicaram que três estados com igual número de provas aplicadas possuem estimativas populacionais completamente diferentes: Amapá (782.295 habitantes), Bahia (15.276.566 habitantes) e Espírito Santo (3.973.697 habitantes). Ao mesmo tempo, Pernambuco, com menos de $1 / 4$ da população de São Paulo, registrou um número superior de processos seletivos para Arquivista. Outra característica que merece destaque é o fato de sete estados não terem apresentado nenhum concurso registrado na base de dados do website consultado. $\mathrm{O}$ maior deles em número de habitantes - o Pará, com 8.272.724 possui pelo menos $23 \%$ a mais de moradores quando comparado a Goiás que, por sua vez, registrou a ocorrência de quatro provas.

Acredita-se que as informações apresentadas são suficientes para afirmar que não há relação proporcional entre o número de habitantes de um estado e a quantidade de concursos lá aplicados. No entanto, tal elemento pode ser considerado um bom indicador para avaliar as necessidades de cada região, visto que um estado mais populoso possivelmente produz mais documentos e tende a receber uma quantidade maior de pedidos de acesso à informação, e o Arquivista é o profissional indicado para lidar com tais demandas.

Todos os resultados e análises descritos foram fruto das informações contidas no conjunto de documentos oriundo do website PCI Concursos e que, embora extenso, pode não representar a totalidade de provas aplicadas para o cargo de Arquivista no Brasil durante o período definido. No entanto, as observações destacadas são de grande relevância para a área por serem um dos primeiros relatos a relacionar Arquivologia e concursos públicos no contexto brasileiro. Espera-se que os dados apresentados possam ser utilizados como ponto de partida para outras pesquisas que busquem analisar as características da profissão nesse setor tão específico do mercado de trabalho.

\section{CONSIDERAÇÕES FINAIS}

Após observar e analisar os dados coletados foi possível identificar que há certo descaso de algumas bancas organizadoras com relação à definição dos temas que devem ou não integrar a seção de conhecimentos específicos das provas. Questões que não tenham relação com as atividades e formação do Arquivista, por exemplo, não deveriam integrar a área da prova reservada para conhecimentos específicos. Caso tal conhecimento seja necessário ao bom desempenho do cargo é indicado que seja cobrado na seção comumente denominada "conhecimentos gerais", onde ficam concentradas as questões que não têm relação direta com o conteúdo específico do cargo para o qual a seleção está sendo feita.

Concursos para Arquivista que contenham nenhuma questão referente à área não podem ser considerados adequados para a escolha de um profissional. No entanto, ao mesmo tempo em que algumas provas cobram temas referentes a outros campos do saber - refletindo a realidade de que nem sempre o conhecimento sobre a disciplina é tido como relevante para que se obtenha uma boa classificação na seleção - outras demonstram o contrário, explorando temas da Arquivologia que não apresentam destaque, mas são fundamentais para o desempenho da profissão.

Em razão do foco deste trabalho ser especificamente analisar aspectos dos concursos para Arquivista, sem fazer relação com os currículos dos cursos de Arquivologia, não é possível concluir se os tópicos mais ou menos abordados se encontram nessas situações devido à influência ou à falta de certas disciplinas nas universidades. Essa conclusão só seria possível por meio da análise de disciplinas da grade curricular de cada curso e uma comparação dessas com os temas exigidos nas provas, o que seria uma excelente forma de afirmar se as bancas organizadoras consideram relevantes ou não os tópicos de estudo dos cursos de graduação, e por isto sinalizamos esta perspectiva como um possível desdobramento dessa pesquisa.

Outra perspectiva de pesquisa a ser desenvolvida é a identificação de temas que não tenham apresentado ocorrência nas provas. Tal investigação possibilitaria constatar se há matérias cujo conteúdo merece maior destaque nas provas por apresentar grande relevância no meio acadêmico, permitindo, 
dessa forma, o incentivo à pesquisa e ao desenvolvimento das diversas ramificações da área. Uma análise aprofundada dos currículos dos cursos, a qual englobasse as referências bibliográficas por eles utilizadas, possibilitaria ainda uma comparação com o material teórico adotado pelas bancas a fim de concluir se são semelhantes ou não.

Os resultados da pesquisa permitiram identificar que há grande escassez na menção de referencial teórico das questões, fato que pode ser prejudicial tanto para a banca organizadora - a qual estará mais vulnerável à interposição de recursos contra as respostas - quanto para o candidato - que poderá errar uma questão devido à utilização de publicação ou autor distinto do que foi pensado pela banca. Tal situação pode ser exemplificada por equívocos que foram constatados mais de uma vez no decorrer da análise, nos quais a banca fez uso de uma referência pouco conhecida, considerando-a como correta, mas também incluiu em uma das opções de resposta a definição de outra fonte mais popular e julgou-a errada.

Nessas circunstâncias, caso a bibliografia fosse citada não haveria margem para questionamentos e provável pedido de revisão do gabarito, mas a falta de objetividade na elaboração dessas questões possibilitou as duas opções de resposta e a consequente anulação da pergunta. Para evitar tais tipos de problemas é necessário que os responsáveis por elaborar as provas reflitam sobre como desenvolver os questionamentos e as opções de resposta com a utilização de critérios objetivos, baseados na literatura da área. A citação de referências ajuda a evitar os erros e a subjetividade, pois reduz consideravelmente as chances de haver dupla interpretação. Considerando que o propósito da elaboração de um concurso é selecionar aqueles mais preparados para assumir o cargo, é importante que os organizadores convirjam esforços para evitar erros como esses citados, caso contrário é possível que os selecionados tenham tido apenas sorte. Outro ponto positivo que pode decorrer da menção às fontes é o fortalecimento da produção científica e o consequente desenvolvimento da área, pois as pessoas terão mais motivos para ler a bibliografia para as provas e, com a leitura, o senso crítico é estimulado e novas ideias surgem, podendo resultar em futuras publicações.

Embora o resultado da análise de bibliografia utilizada nas provas demonstre que há um número superior de citações da legislação (38\%), quando comparada às obras de referência da Arquivologia (15\%), é importante destacar que, dentre estas, as publicações brasileiras representam $65 \%$, número bastante significativo considerando que grande parte das técnicas e princípios da disciplina foram desenvolvidos por pesquisadores internacionais. Espera-se que tal resultado possa servir de incentivo aos autores brasileiros e estimular a produção de conhecimento nacional.

Já o resultado da análise de distribuição geográfica das provas apresentou uma tendência de concentração dos concursos próxima aos grandes centros urbanos do país. Embora essa conclusão possua algumas exceções, indica que a contratação de Arquivistas nos órgão públicos afastados das grandes capitais não é feita com frequência. No entanto, tal apontamento só poderia ser confirmado com o desenvolvimento de uma pesquisa no quadro de pessoal dessas instituições buscando verificar a existência e o preenchimento, ou não, das vagas. Considerando a conclusão de que a localização das provas aparenta seguir o padrão de distribuição dos cursos de Arquivologia no país, é possível supor que poderia haver uma maior oferta de concursos caso o número de cursos fosse superior.

Ainda que o material coletado para a elaboração desta pesquisa seja proveniente de uma única fonte em um espaço temporal específico, acredita-se, devido à quantidade de provas analisadas, que os resultados aqui obtidos representam a realidade dos concursos públicos para Arquivista no Brasil. Conforme mencionado, há diversos pontos que merecem revisão por parte das bancas organizadoras e se espera que os dados e resultados apresentados possam, de alguma forma, contribuir para a adequação das provas a uma realidade que valorize cada vez mais a produção científica e estimule o desenvolvimento da área.

Há diversos temas de pesquisa que poderão ser oriundos das conclusões aqui apontadas, além daqueles já mencionados. É importante que as investigações que relacionem o Arquivista com o seu mercado de trabalho sejam incentivadas e tenham visibilidade para fazer com que o profissional possa conhecer cada vez mais as suas opções e, assim, identificar eventuais necessidades e oportunidades, contribuindo para o desenvolvimento da disciplina e o reconhecimento da profissão. 
Artigo recebido em: 14/05/2017

Aceitação definitiva em: 26/09/2017

\title{
AN STUDY ABOUT CIVIL SERVICE EXAMS FOR ARCHIVIST IN BRAZIL
}

\begin{abstract}
The objective of the study was to make an analysis of different aspects related to civil service exams for Archivists in Brazil, looking to recognize the relationship between the main subjects required in the questions and the archival theoretical reference. As methodological procedures, identified the areas of greater prominence of Archival Science in the scope of the questions and developed qualitative and quantitative surveys of the results, as well as analysis of the geographical distribution of the tests. The data showed that topics are not required at the same proportion and that certain important topics are neglected, at the same time as the citation of bibliography is scarce. The results indicated that there is a greater concentration of exams for Archivists in regions where there is a graduation course in the area.
\end{abstract}

Keywords: Archival Science. Civil Service Exam. Geographical Mapping. Theoretical Reference.

\section{REFERÊNCIAS}

ARQUIVO NACIONAL (Brasil). Dicionário Brasileiro de Terminologia Arquivística. Rio de Janeiro: Arquivo Nacional, 2005

BELLOTTO, Heloísa Liberalli. Arquivos: estudos e reflexões. Belo Horizonte: Editora UFMG, 2014.

\section{BRASIL. Constituição da República Federativa} do Brasil de 1988. Brasília, DF: Senado Federal: Centro Gráfico, 1988. Disponível em:

<http://www.planalto.gov.br/ccivil_03/constituicao/ ConstituicaoCompilado.htm>. Acesso em: 25 abr. 2017.

. IBGE. Estimativas populacionais para os municípios e para as Unidades da Federação brasileiros em 01.07.2016. Disponível em: <http://www.ibge.gov.br/home/estatistica/populacao /estimativa2016/default.shtm>. Acesso em: 15 abr. 2017.
Lei no 12.527 de 18 de novembro de 2011. Brasília: Diário Oficial da União, 2011. Disponível em:

<http://www.planalto.gov.br/ccivil_03/_ato20112014/2011/lei/112527.htm>. Acesso em: 16 abr. 2017.

CAVALLINI, M. Conhecimentos específicos decidem vaga: veja como se preparar. São Paulo: G1, 2008. Disponível em:

<http://g1.globo.com/Noticias/Concursos_Empregos /0,,MUL388988-9654,00-

conhecimentos+especificos+decidem+vaga+veja+c omo+se+preparar.html>. Acesso em 29 abr. 2017.

CONARQ, Conselho Nacional de Arquivos. e-Arq: modelo de requisitos para sistemas informatizados de gestão arquivística de documentos: versão 1.1. Rio de Janeiro: Arquivo Nacional, 2011.

. NOBRADE: Norma Brasileira de Descrição Arquivística. Rio de Janeiro: Arquivo Nacional, 2006. 
CONSELHO INTERNACIONAL DE ARQUIVOS.

ISDF: Norma internacional para descrição de funções. Tradução de Vitor Manoel Marques da Fonseca. 1. ed. Rio de Janeiro: Arquivo Nacional, 2008

ISAAR(CPF): norma internacional de registro de autoridade arquivística para entidades coletivas, pessoas e famílias/tradução de Vitor Manoel Marques da Fonseca. 2. ed., Rio de Janeiro: Arquivo Nacional, 2004.

. ISAD(G): Norma geral internacional de descrição arquivística: segunda edição, adotada pelo Comitê de Normas de Descrição, Estocolmo, Suécia, 19-22 de setembro de 1999, versão final aprovada pelo CIA. - Rio de Janeiro: Arquivo Nacional, 2000.

COUTURE, C.; MARTINEAU, J.; DUCHARME, D. A formação e a pesquisa em arquivística no mundo contemporâneo. Tradução Luís Carlos Lopes. Brasília: Finatec, 1999. 190 p.

JARDIM, J. M. A pesquisa em Arquivologia: um cenário em construção. In: VALENTIM, Marta Lígia Pomim (Org.). Estudos avançados em arquivologia. Marília: Oficina Universitária; São Paulo: Cultura Acadêmica, 2012. p. 135-153.

ROUSSEAU, Jean-Yves; COUTURE, Carol. Os fundamentos da disciplina arquivística. Lisboa: Dom Quixote, 1998.

SILVA, Armando Malheiro da; et al. Arquivística: teoria e prática de uma ciência da informação. Porto: Edições Afrontamento, 1998

SILVA, Armando Malheiro da. A Informação: da compreensão do fenômeno e construção do objecto científico. Porto: Edições Afrontamento, 2006 